\title{
The Impact of Job Stress on Deviant Workplace Behaviour: A Study of Operational Level Employees of Comfort Apparel Solutions Company in Sri Lanka
}

\author{
H. Michelle S. V. Silva \\ Lecturer, Department of Human Resource Management \\ Email: michellevindya@kln.ac.lk \\ R. M. I. D. Ranasinghe \\ Department of Human Resource Management \\ University of Kelaniya, Sri Lanka \\ Email: idilranasinghe@gmail.com
}

Faculty of Commerce and Management Studies, University of Kelaniya, Sri Lanka

Received: January 16, 2017 Accepted: February 15, 2017 Published: March 11, 2017

doi:10.5296/ijhrs.v7i1.10901 URL: http://dx.doi.org/10.5296/ijhrs.v7i1.10901

\begin{abstract}
Although the direct effect of job stress on deviant workplace behavior is well documented, previous theoretical explanations and empirical findings of the relationship has been inconsistent. Thereby, drawing on General Strain Theory the current study attempts to examine the effect of job stress on deviant workplace behavior by exploring the dimensions of job stress effect of work overload, role conflicts and role ambiguity. The study was quantitative and a cross-sectional survey design was followed. Data was collected through a structured questionnaire. Convenience sampling technique was applied to select the sample, and the final sample consisted of 200 operational level workers from Comfort Apparel Company in Sri Lanka. It was found that job stress is significantly impact on deviant workplace behavior. Further, work overload, role conflict and role ambiguity are found positive significant relationship with deviant workplace behavior. Nevertheless among the dimensions of job stress, work overload and role conflict are identified as dimensions which have significant impact on deviant workplace behavior, exempt role ambiguity. Finally, it is concluded that though role ambiguity causes to Deviant workplace behavior it has
\end{abstract}


insignificant impact on deviant workplace behavior and work overload and role conflict have made significant impact on deviant work place of operational level employees of Comfort Apparel Solutions Company in Sri Lanka. The study concludes that job stressors must be considered when employees are performing deviant workplace behavior. It is suggested that managers and practitioners establish culture which free from job stressors to eliminate workplace deviance.

Keywords: Deviant workplace behavior, Work overload, Role conflicts, Role ambiguity, General stain theory.

\section{Introduction}

In reviewing literature on Deviant Workplace Behaviour (DWB), According to Appelbaum, Iaconi and Matousek (2007), specified that in the place of work lot of people come together and express diverse behaviours. Each of these behaviours has various effects to the individuals who are working for the organization as well as to the whole organization. In the ideal instance these behaviours happen together with the norms of the organizations. The organizational norms are a create comprising with languages, expected behaviours, beliefs and principles which allow the workplace to behave at a preferred situation. Nevertheless, truth is not always the ideal case; work behaviour can also vary from the norms of the organization. Employees whichever lack the motivation to follow to normative expectations of the social content or become motivated to violate those expectations.

The results of deviant behaviour at work are serious, as they can affect all levels of organizations, containing with productivity, decision-making and financial costs (Appelbaum et al., 2007).

Peterson (2002) explained that DWB is an occupational crime. In addition Bennett \& Robinson (2000) stated that may vary along a range of severity, from minor acts such as leaving early and embarrassing co-workers to serious acts, such as sabotage and theft from organization. However, when normal behaviour of worker's goes outside from the norms of the organization is concerned deviant. A behaviour can be a workplace deviant if it violates the norms, major rules, policies and internal regulations of organizational life and that may threaten to the well-being of the organization or its members or both (Bennett \& Robinson, 2000; Spector \& Fox, 2002).

Moreover the negative deviance is explicit or implicit, whether it involves sexual harassment, spreading rumors, aggression, damage, and corporate sabotage or otherwise, unauthorized organizational behaviour has negative consequences for the entire entity (Bennett \& Robinson, 2000).

And its results are far-reaching and affect overall organization including its decision-making processes, productivity and financial costs (Coccia, 1998). Deviant behaviour of employees has been given high priority in many organizations nowadays.

The management of negative deviant behaviour in the workplace is the one of growing 
concern in organizations globally. To prove this state Bennett and Robinson (2000) calculated that bullying (a form of deviant workplace behaviour) costs Australian employers between 6 to 13 billion Australian dollars each year. And it has been liable for $30 \%$ to $50 \%$ of all business failures in the United States of America (Cousins, Mackay, Clarke, Kelly \& McCary, 2004). Peterson (2002a) identified that in the United States produces organizational losses estimated to reach up to $\$ 200$ billion annually because of the consequences of deviant workplace behaviour.

Categorizations of deviant behaviour were proposed by the many authors. Among them, Robinson and Bennett in 1995 introduced a typology of deviant workplace behaviour including the interpersonal phase. The context consists of the following two dimensions namely Minor vs. Serious which means the severity of the deviant behavior and Interpersonal vs. Organizational. According to Peterson (2002a), by joining these two dimensions, represents the target of the deviant behaviour. And can be categorized in four different types of deviance. They are Production Deviance, Property Deviance, Political Deviance, and Personal Aggression.

The four quadrants might propose that behaviours from one quadrant are isolated to those in another. In case it means that deviant behaviours begin small but increase into different set of behaviour. Minor occurrences of incivility can direct to aggression and the results can be eventually unexplained absences and activities against the organization (Everton Jolton \& Mastrangelo, 2007).

Robinson \& Benett (1995), explained production deviance consist with behaviours that violate the officially prohibited norms which defines the low quality and quantity of work to be experienced. Leaving early, being late to work, wasting resources, taking excessive breaks, using drugs and alcohol in the workplace, calling in sick when well (absenteeism) and withholding effort are production deviance forms.

According to Robinson and Benett in 1995, indicated that property deviance describes unauthorized actions occurrences where employees damage or catch the assets or tangible property of the working organization. The organizations are harmed by property deviance.

Lying about hours worked, intentional errors, accepting kickbacks, sabotaging equipment, releasing confidential information, stealing from the company and misusing expense accounts are the forms of property deviance. Some of these behaviours are connected with direct costs for the organization.

Political deviance is the behaviour as engagement in social interaction that puts other individuals at a personal or political disadvantage. Workplace incivility, showing favoritism, gossiping about co-workers, and competing non-beneficially are forms of political deviance (Robinson \& Benett ,1995).

Personal Aggression means violence that is start up by co-workers can happen everywhere. No industry, no organization, and no employee can ignore the happening of such behaviour. Personal aggression is behaving in an aggressive way towards other individuals. Verbal abuse, sabotaging the work of co-workers, sexual harassment, physical attacks, rape, stealing from 
co-workers, destroying property of co-workers, and threatening co-workers are forms of personal aggression (Robinson \& Benett, 1995; Everton et al., 2007).

Many individual factors affect to this Deviant Workplace Behaviour. Chen and Spector (1992) stated that job stress has many negative effects on an organization and its members. Many researchers found today's working environment characterized by employees changing jobs frequently, unmanageable heavy workloads, new technologies, higher job expectations, job insecurity, continual downsizing efforts of organizations and the increased uncertainty, all of which are causing to increase stress in the work place (Belal, 2009). When workers fail to cope with these stressful situations and conditions, occupational stress will become a health risk (Hellgren, Sverke, \& Isaksson, 1999). Common examples of job stressors at workplace are role conflict and ambiguity (Kahn, Wolfe, Quinn, Snoek,\& Rosenthal, 1964).

Peterson (2002) argued that job stress is the damaging physical and emotional response that occurs when there is a mismatch between capabilities and job demands, resources or needs of the employee. Further Beehr (1976) presented some different aspect for the job stress as a condition which will force a person to deviate from normal working due to change in his/her psychological and/or physiological condition, such person is forced to deviate from normal functioning. This study will look into the three common dimensions of work stressors that have been mostly referred by organizational behaviour scholars (e.g. Rizzo, House \& Lirtzman, 1970; Robbins, 2003) namely, work overload, role conflict and role ambiguity.

According to Rizzo et al. (1970), work overload means having too much works to do in a given amount of time period (Conley \& Woosley, 2000). The mismatch among the requirements, time limits and resources related to work available to reach these targets is known as work overload. And role conflict is incompatibility between expectations of communicated and the observed role performance. Incompatibility among the requests of customers and supervisors cause to generates a situation of role conflict. In general, an aggressive condition of opposition, disagreement or incompatibility between two or more parties can be defined as conflict.

The other factor which has impact on job stress at workplace is role ambiguity. At the job an employee feels more role ambiguity when he has not clear information about the expectations of his or her role (Rizzo et al., 1970). When there is no clear information about employee role requirements, how to meet those requirements, and about the existing evaluative techniques to make sure that the role is being achieved successfully then there exists role ambiguity.

Current study used General strain theory (GST) as base theory. GST seeks to identify the stresses or strains that would cause deviant behavior (Agnew, 1992). The occurrence of deviant behavior is in part of strains which foster negative emotions such as anger, frustration, and depression (stressors). Thus, the negative emotions create pressure for corrective action or deviant behavior is ways of some individuals respond. GST focuses on factors of strain such as the negative treatment by others, work overload, interpersonal relationships, role conflict, role ambiguity, inability to achieve goals, and the loss of valued possessions.

A number or researchers have supported a positive relationship between work overload and 


\section{Macrothink}

DWB. According to Robinson and Bennett (1995) found that significant relationships between work overload and DWB. Furthermore work over overload is identified as the amount of work which an individual has to finish within a given period of time (Chen \& Spector, 1992) and excessive workload or role overload is one of the job stressors or task-related stressors (Spector \& Fox, 2002). Past researches have presented that work overload has a significant relationship with deviant workplace behavior. Employees are likely to expose deviant workplace behaviors in response to their job stressors. In recent times most of the researches pay attention to impact of job stress on Deviant Workplace Behaviour. In Sri Lanka only very few studies relate to job stress and Deviant Workplace Behaviour. Thus, the purpose of this study is to test the impact of job stress (in the form of work overload, role conflict and role ambiguity) on Deviant Workplace Behaviour behavior of operational level employees those who work in well reputed apparel sector company in Sri Lanka. In order to achieve above purpose, researcher has developed four hypotheses with the aid of literature as follows.

H1: There is an impact from Job Stress on DWB.

H1a: There is an impact from Work Overload on DWB.

H1b: There is an impact from Role Conflict on DWB.

H1c: There is an impact from Role Ambiguity on DWB.

Based on above four hypotheses, the conceptual framework of the study is as follows:

Figure 1: Relationships between Job Stress and Deviant Workplace Behaviour

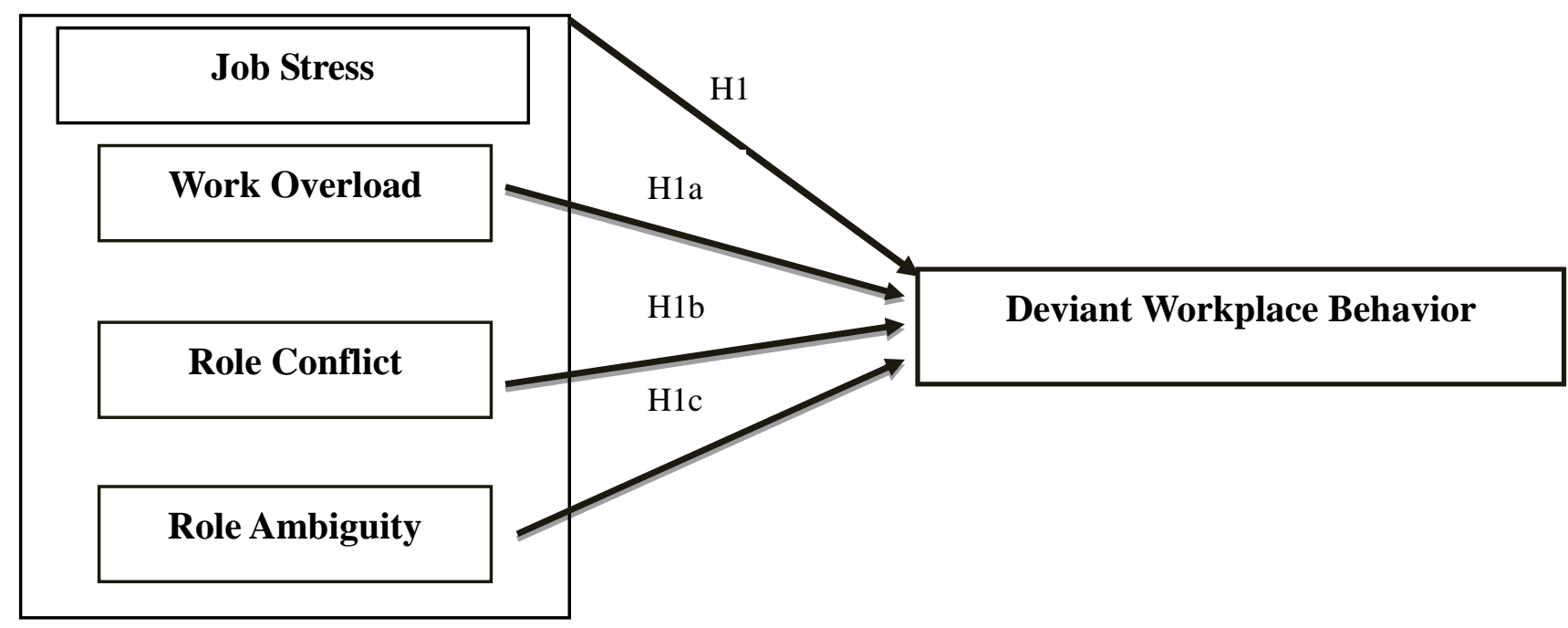

Source: Author

\section{Methods and Materials}

Researcher has selected the compelling key player in appeal sector organization in Sri Lanka as the research context. Based on the ethical consideration hypothetical name was used by researcher as Comfort Apparel Solutions Company in Sri Lanka. This was cross-sectional 
study since data was collected in a particular point of time and it did not repeat. Since this study is quantitative deductive study, this study has adapted survey research method. Thus self-administered questionnaire was used to collect data as a survey instrument in this study. The questionnaire for measuring job stress are taken 'stress measurers' from Beehr et al. (1976) and for work overload, role ambiguity and role conflict measures used from Rizzo et al. (1970). To measure the level of DWB, researcher used the scale which was developed by Bennett and Robinson, (2000), topic on 'Development of a measure of workplace deviance'. Pilot test was conducted with 15 participants and made some adjustments for the final version of the questionnaire accordingly.

The potential respondents of this study are operational level workers who currently working in Comfort Apparel Solutions Company in Sri Lanka. Two Hundred operational level workers represented in the sample. This study has used the convenience sampling technique to select operational level workers. Out of which 168 operational level workers were returned their questionnaires and 15 questionnaires have been rejected on the basis of incomplete information. However 153 completed questionnaires were considered for the data analyze process. The response rate of the questionnaire survey was high. It was $84 \%$ and $76.5 \%$ of response rate and effective rate of this study.

After permission was received from the relevant authorities, data collection was carried out with operational level workers at Comfort Apparel Solutions Company in Sri Lanka. Anonymity and confidentiality are highly ensured by the researcher during the survey. And the company name was not revealed because of the ethical reasoning.

\section{Data analyses and Presentation}

\subsection{Demographic Information}

The survey data described that majority of $73.2 \%$ respondents were males $(\mathrm{N}=112)$ and female operational level workers were $26.8 \%(\mathrm{~N}=41)$ based on the company nature. In terms of age, the majority of respondents were between 23 and 33 years of age in 41.2 percent, 23.5 percent represented between 34 to 44 age ranges, 19.6\% youngest workers represented in 22 years or below and $15.7 \%$ representation from eldest age range. With respect to marital status, $64.7 \%$ of the respondents were married, $32 \%$ were unmarried and other $3.3 \%$ were Divorced or widowed. According to the demographic data $25.5 \%$ of the respondents have been below the G.C.E.O/L qualification, $21.6 \%$ have been passed the G.C.E.O/L examination. Moreover, only $10.5 \%$ of respondents were completed professional courses relevant for their careers. The working experience of operational level workers at the present job is $30.1 \%$ respondents reported that they have worked for 3 to 4 years and $23.5 \%$ have less than one year experience $(\mathrm{N}=36) .39$ number of operational level workers $(20.9 \%)$ reported that they have worked for 1 to 2 years in their job. With respect to the place of work, more than quarter of the respondents had worked on the current working place for more than five years $(\mathrm{N}=39,25.5 \%)$.

\subsection{Preliminary Analyses}

According to Kline (2005), a rule of thumb for total value of skew index is less than 03 and kurtosis value less than 10 was used to test the normality of the data distribution. The results 


\section{Macrothink}

International Journal of Human Resource Studies

ISSN 2162-3058 2017, Vol. 7, No. 1

indicate that the sample data is normally distributed. Scatter plot diagram was drawn to examine linearity between variables and scatter plots took an approximately linear according to the visual inspection.

Reliability was examined with Cronbach's Alpha test. Accordingly, all values of reliability are greater than 0.7 which show high reliability in measures. The results of Cronbach's Alpha test are given in the table below, which suggest that the reliability of each instrument is satisfactory.

Table 01: Reliability of construct measures

Measures Cronbach's AlphaN of Items

Deviant Workplace Behavior.981

Job Stress

Work Overload

Role Conflicts

Role Ambiguity

.708

4

Source: Survey Data, 2016

Moreover the Pearson Product Moment Correlation Coefficient was performed to identify the relationship between deviant workplace behavior and job stress at Comfort Apparel Solutions Company in Sri Lanka. Correlation between job stress and DWB has .915 and it reflects strong positive relationship between two constructs according to the criteria provided by Field (2009).

\subsection{Hypotheses Testing}

The hypothesis testing was carried out by using multiple regression analysis. As all the hypotheses were concerned with significant impacts, two- tailed test was used. First simple regression was performed to test the Impact of job stress on deviant workplace behaviour of operational level employees working at Comfort Apparel Solutions Company in Sri Lanka. 
Table 02: Model parameters of hypotheses - Measuring Impact of job stress on deviant workplace behavior

Model Standardized Coefficients B t Sig.

$\begin{array}{lll}\text { Job Stress } & .915 & 27.813 \quad .000\end{array}$

a. Dependent Variable: Deviant Workplace behavior

Source: Survey Data, 2016

Table 03: Model summary of hypotheses - Measuring Impact of job stress on deviant workplace behavior

ModelR R SquareAdjusted R SquareStd. Error of the Estimate

$\begin{array}{llll}1 & .915^{\mathrm{a}} .837 \quad .836 & .42546\end{array}$

a. Predictors: (Constant), Job Stress

Source: Survey Data, 2016

\subsection{Model Parameters}

The first simple regression was performed to test the effect of job stress on deviant workplace behavior of operational level workers. According to Field (2009)the b values give the contribution of each predictor to the model. The standardized beta $(\beta)$ for deviant workplace behavior indicates if the effect of the control variable is held constant, there is a positive impact from job stress on deviant workplace behavior of operational level workers, and the degree it affects deviant workplace behavior of them is .915. It means that when job stress of operational level workers increase by one standard deviation deviant workplace behavior of operational level workers increase by .915 standard deviations in level of significant at .000 which is less than the level of .05 .

\subsection{Model Summary}

Model 1 indicates that, R .837 is the Correlation Coefficient of the independent variable with the dependent variable after all the inter correlations are taken into account. R Square .837 is the explained variance in DWB by the combination of this variable is significant at .000 level.

The results indicate that $83.7 \%$ of the variance of DWB of operational level workers at Comfort Apparel Solutions Company in Sri Lanka. Hence it can be clearly said that other factors have $16.7 \%$ influences on DWB. 
According to the research findings, there is a strong significant impact of job stress on Deviant workplace behavior. Therefore, alternative hypothesis $\left(\mathrm{H}_{1}\right)$ was accepted.

According to Field (2009), the figures in Table below indicate that the tolerance is far greater than .1 and the VIF is far less than 10 for each predictor. These values in above table reveals that no multicollinearity between dimensions of job stress and assure that remedial actions are not required as well.

Table 04: Model parameters of hypotheses - Measuring Impact of dimensions of job stress on deviant workplace behaviour

\begin{tabular}{lllllll}
\hline Model & Standardized Coefficients & $\mathrm{t}$ & Sig. & \multicolumn{2}{l}{ Collinearity Statistics } \\
Beta & & & & Tolerance & VIF \\
\hline Work Overload & .619 & 7.991 & .000 & .158 & 6.313 \\
Role Conflict & .302 & 4.202 & .000 & .185 & 5.411 \\
Role Ambiguity & .034 & .743 & .459 & .451 & 2.216 \\
\hline
\end{tabular}

Source: Survey Data, 2016

From the above table can be seen that when the other variables are controlled only Work Overload and Role Conflict show significant impact on DWB of operational level workers of Comfort Apparel Solutions Company in Sri Lanka, in which the standardized beta $(\beta)$ coefficients increases by .619 and .302 respectively and significant at .00 which is less than the level of .05. Thus, the results of table 4 reveals that there is a positive impact from work overload and role conflict on deviant workplace behaviour. Hence H1a and H1b hypotheses were accepted. Moreover results were concluded that Work Overload is the most influenced factor to the DWB and it is significant at .000 level. Nevertheless Role Ambiguity's Sig value indicates .459 that is more than the value of .05 , hence it is insignificantly predictive of DWB. Thus finally, the first three hypotheses were supported exempt H1c hypothesis, within operational level workers of Comfort Apparel Solutions Company in Sri Lanka.

\section{Limitations of the Study}

In identifying the factors relating to the both the dimensions of job stress and Deviant Workplace behavior, it is very important to have a through literature review which supports the study in Sri Lankan context. But lack of existing local literature does not support to understand the previous experience related to this study. This carries a limitation of having lack local literature. Further, the primary data was collected through questionnaire only. Through pilot survey researcher could be able to decide on basic information and these measure used to continue the research. Thus researcher only depends on primary data gathered through questionnaire when analyzing the study. 
Moreover, the sample employees of the study are only from the private sector organization while considering other business entities facing GC. Therefore, the conclusions and findings cannot be generalized to organizations other than private sector. Limited access to the sample so researcher could use only convenience sampling technique .Only the operational level workers are identified as correspondents. This omits the team leaders, supervisors, non-staff and other staffs working in the company. Furthermore Operational workers, who are normally working under manpower companies, are not considered for the study as most of the time they are not providing their services continuously.

The limitations turn primarily around sampling issues. Having a larger sample from operational workers may change the results of this study.

The risk of respondents' biasness is another limitation of this study. The use of self-reporting methods can be regarded as problematic as the reliability of the responses relies heavily on the truthfulness of the answers of the respondent. With this type of method a possibility of overstated responses could take place. And the possibility of the operational level workers being reluctant to express their real feelings and behaviors emotions as they may consider they are being criticized; will limit the quality of primary data.This study was quantitative and measured impacts of variables. Longitudinal study suited for this kind of researches. Researcher conducted cross sectional analysis because of the time constraint.

\section{Directions for Future Research}

Further, research regarding "the impact of DWB" should be conducted since there were no studies done in this regard in Sri Lankan context. This study covered the impact of JS on DWB in the Comfort Apparel Solutions Company in Sri Lanka. Future researchers can also pay an attention on the impact of JS on DWB in other industries.

The current study measured DWB based on job stress factors. Further research could be conducted using other variables such as job satisfaction, personality characteristics, interpersonal relationship and influence on supervisors etc. which are affected to the DWB. As well as Researchers can also be done to investigate the potential influence of DWB effects of selected individual level variables like seniority, academic rank, race, religion and organizational level variables as size, public versus private status, different geographic region, and overall satisfaction level. As well as researchers can perform this in different sector organizations or different industries such as public and private sector organizations, different industries such as Banking industry, Insurance industry and Service industry etc.

Furthermore, data collection technique should be redesigned and could be conducted using another type of instruments or varied types of instruments. In addition, research should be carried out to further investigate how organizations can minimize the effects of negative workplace deviance as well their origins, and study how organizations can foster positive deviance in their employees. It leaves the floor open to a number of questions that need to be further addressed. 


\section{Conclusion}

This research makes an effort to show that job stress of employees seriously effects on employees to act deviant behaviors in workplace. The findings specify that there is significant impact of job stress on deviant workplace behaviour. Further work overload and role conflict also shown the significant impact on DWB exempt role ambiguity. Moreover results were concluded that Work Overload is the most influenced factor to the DWB and it is significant at .000 level. Therefore, Managers should pay high attention on work overload and role conflict rather than role ambiguity when try to eradicate the deviant workplace behaviour of operational level workers in Comfort Apparel Solutions Company in Sri Lanka.

\section{References}

Agnew, R. (1992). Foundation for a general strain theory of crime and delinquency. Criminology, 30(1), 47-88.

Appelbaum, S.H., Iaconi, G.D. and Matousek, A. (2007). Positive and negative deviant workplace behaviors: causes, impacts, and solutions, Corporate Governance, 7(5), 586-598.

Belal, B. H. Y. R. M., (2009). Religiosity and work stress coping behavior of Muslim employees, Education, Business and Society: Contemporary Middle Eastern Issues, 2 (2), $123-137$.

Bennett, R. J. \& Robinson, S. L. (2000). Development of a measure of workplace deviance, Journal ofApplied Psychology, Vol. 85, No. 3, pp. 349-360.

Chen, P.Y. \& Spector, P.E (1992). Relationships of work stressors with aggression, withdrawal, theft and substance use: An exploratory study. 1 Occupational and Organizational Psychol, 65,177-184.

Coccia, C. (1998). Avoiding a toxic organization. Nursing Management, 29(5), 32-34.

Conley, S. \& Woosley, S. (2000).Teacher role stress, higher order needs and work outcomes, Journal of Educational Administration, 38 (2), 179-201.

Cousins, R., MacKay, C. J., Clarke, S. D., Kelly, C., Kelly, P. J. \& McCaig, R. H. (2004). Management Standards work-related stress in the UK: practical development, Work Stress, 113-136.

Everton, W.J., Jolton, J.A. and Mastrangelo, P.M. (2007). Be nice and fair or else: understanding reasons for employees deviant behaviors, Journal of Management Development, 26 (2), 117-131.

Field, A. (2009). Discovering statistics using SPSS. Sage publications.

Greenberg, L. and Barling, J. (1996). Employee Theft, Journal of Organizational Behavior, 49-64.

Hellgren, J., Sverke, M. \& Isaksson, K. (1999). A two-dimensional approach to job insecurity, 


\section{Macrothink \\ International Journal of Human Resource Studies \\ ISSN 2162-3058 2017, Vol. 7, No. 1}

46, 22-36.

Kahn, R. L., Wolfe, D. M., Quinn, R. P., Snoek, D., \& Rosenthal, R. A. (1964). Organizational stress: Studies in role conflict and ambiguity. New York: Wiley.

Peterson, D.K. (2002a). Deviant Workplace Behavior and the Organization's Ethical Climate", Journal of Business and Psychology, 7, 47-61.

Rizzo, J.R., House, R.J. \& Lirtzman, S.I. (1970). Role conflict and ambiguity in complex organizations.

Robinson, S. L., \& Bennett, R. J. (1995). A typology of DWBs: a multidimensional scaling study. Academy of Management Journal, 38, 555-572.

Robinson, S.L. \& Greenberg, J. (1998). Employees Behaving Badly: Dimensions, Determinants, and Dilemmas in the Study of Workplace Deviance, Journal of Organizational Behavior (1986-1998), 1-30.

Spector, P. E., \& Fox, S. (2002). Building an integrative model of extra role work behaviors: A comparison of counterproductive work behavior with organizational citizenship behavior. International Journal of Selection and Assessment, 10, 51-57.

\section{Copyright Disclaimer}

Copyright for this article is retained by the author(s), with first publication rights granted to the journal.

This is an open-access article distributed under the terms and conditions of the Creative Commons Attribution license (http://creativecommons.org/licenses/by/3.0/). 